\title{
$\beta$-glycosphingolipids ameliorated non-alcoholic steatohepatitis in the Psammomys obesus model
}

\author{
Ehud Zigmond ${ }^{1, *}$ \\ Oshrat Tayer-Shifman ${ }^{1, *}$ \\ Gadi Lalazar' \\ Ami Ben Ya'acov' \\ Sarah Weksler-Zangen ${ }^{2}$ \\ David Shasha' \\ Miriam Sklair-Levy ${ }^{3}$ \\ Lidya Zolotarov' \\ Zvi Shalev' \\ Rony Kalman ${ }^{2}$ \\ Ehud Ziv² \\ Itamar Raz ${ }^{2}$ \\ Yaron Ilan' \\ 'Liver Unit, ${ }^{2}$ Diabetes Unit, \\ ${ }^{3}$ Department of Radiology, \\ Hebrew University-Hadassah \\ Medical Center, Jerusalem, Israel \\ *These authors contributed equally to \\ this work
}

This article was published in the following Dove Press journal:

Journal of Inflammation Research

8 October 2014

Number of times this article has been viewed

\begin{abstract}
Liver steatosis is a common characteristic of obesity and type 2 diabetes, and fatty liver disease is increasingly recognized as a major health burden. Accumulating evidence suggests that $\beta$-glycosphingolipids play an important role in insulin sensitivity and thus could affect hepatic steatosis. To determine the effect associated with $\beta$-glycosphingolipid-mediated amelioration of liver injury, seven groups of Psammomys obesus on a high-energy diet were studied. Animals were treated with daily injections of $\beta$-glucosylceramide, $\beta$-lactosylceramide, or a combination of both. $\beta$-glycosphingolipids ameliorated the hepatic injury manifested by decreased liver enzymes, liver weight, and hepatic fat, and improved liver histology. Administration of both $\beta$-glucosylceramide and $\beta$-lactosylceramide also decreased interferon (IFN)- $\gamma$ serum levels. These effects were associated with improved serum cholesterol and triglyceride levels. These data suggest that $\beta$-glycosphingolipids ameliorate liver injury in an animal model of nonalcoholic steatohepatitis.
\end{abstract}

Keywords: NAFLD, glycolipids, STAT, NASH, insulin resistance, diabetes

\section{Introduction}

Nonalcoholic fatty liver disease (NAFLD) is an increasingly recognized condition that includes a spectrum of clinical and pathological conditions ranging from steatosis to cirrhosis and liver failure. NAFLD is associated with obesity and especially central adiposity, insulin resistance, metabolic syndrome, and type 2 diabetes. ${ }^{1}$ The interplay between these factors is not well understood, making it difficult to establish therapeutic strategies. ${ }^{2}$

NAFLD has been studied in several animal models. Some of these involve nutritional manipulation, including high-fat, high-fructose/sucrose, and methionine-cholinedeficient (MCD) diets. ${ }^{3}$ These diets result in several of the features of nonalcoholic steatohepatitis (NASH), including fatty liver, inflammation, mitochondrial dysfunction, evidence of insulin resistance, increased cytochrome P4502E1, and oxidative stress. ${ }^{4}$ The Zucker diabetic fatty (ZDF) $f a / f a$ rat, a model of congenital leptin resistance, ${ }^{4,5}$ and the $o b / o b$ leptin-deficient mouse ${ }^{6}$ share some features with the disease in humans. Studies in these models have uncovered several basic mechanisms that explain the dysfunction occurring in different types of liver cells during the metabolic syndrome, some of which have important therapeutic implications for treating human NASH. ${ }^{6}$ However, none of these models resemble NASH disease development in humans. ${ }^{3}$

The sand rat Psammomys obesus, a member of the gerbil subfamily, serves as a model for nutritionally induced type 2 diabetes characterized by primary insulin resistance..$^{7-9}$ P. obesus is adapted to life on a low-energy (LE) diet, characterized

Correspondence: Ami Ben Ya'acov Liver Unit, Hebrew UniversityHadassah Medical Center, Ein-Karem, POB I200, Jerusalem, Israel $\mathrm{Tel}+97226777650$

Email amib@hadassah.org.il 
by a thrifty metabolism. When transferred to a high-energy (HE) diet, these animals develop obesity, hyperinsulinemia, hyperglycemia, and hypertriglyceridemia. ${ }^{10,11}$ Increased hepatic triglyceride production and apolipoprotein B induction have been demonstrated in hyperinsulinemic P. obesus. ${ }^{12,13}$ Recent reports have also suggested the presence of hepatic steatosis in P. obesus fed an HE diet. ${ }^{11}$

Despite the recognition of an immune component in NASH pathogenesis, few studies have examined the therapeutic potential of administering immunomodulatory agents to treat this disorder. $\beta$-glucosylceramide (GC) and $\beta$-lactosylceramide (LC) are intermediates in the metabolic pathways of complex glycosphingolipids. ${ }^{14}$ These molecules and other glycosphingolipids were shown by others and by us to affect the relationship between hepatic steatosis and insulin resistance. ${ }^{15-19}$

The aims of the present study were to characterize hepatic steatosis in $P$. obesus and to determine the effect of $\beta$-glycosphingolipids on hepatic steatosis and the metabolic syndrome in this model. P. obesus fed the HE diet were found to have a high hepatic fat content, significant zone 3 steatosis, mild inflammation, and mild fibrosis on liver biopsies, as well as elevated serum transaminases. Administering $\beta$-glycosphingolipids induced a profound decrease in liver enzymes and in liver mass. These effects were accompanied by amelioration of hepatic steatosis and decreased serum cholesterol, triglycerides, and interferon (IFN)- $\gamma$.

\section{Methods}

\section{Animals}

Five-month-old male $P$. obesus were purchased from Harlan laboratories (Jerusalem, Israel). Animals were housed in solid-bottomed polypropylene cages equipped with water bottles and Aspen woodchip bedding, and were fed standard LE $(2.38 \mathrm{kcal} / \mathrm{g})$ or HE (2.93 kcal/g) artificial diets. Animal experiments were carried out in accordance with the guidelines of the Hebrew University-Hadassah Institutional Committee for Care and Use of Laboratory Animals and with the committee's approval.

\section{Preparation of glycolipids}

$\beta$-GC and $\beta$-LC were purchased from Avanti Polar Lipids (Alabaster, AL, USA) and dissolved in ethanol. They were then emulsified in phosphate buffered saline (PBS).

\section{Study groups}

We studied seven groups of five-month-old $P$. obesus on an HE diet ( $n=8$, Table 1). Animals were treated for 25 days with daily intraperitoneal injections of $\beta$-glycolipids: GC, LC, or
Table I Experimental and control groups

\begin{tabular}{|c|c|c|c|}
\hline Group & Treatment & Dose (mg/kg) & Diet \\
\hline $\bar{A}$ & GC & 2.5 & $\mathrm{HE}$ \\
\hline B & LC & 2.5 & $\mathrm{HE}$ \\
\hline C & IGL & 2.5 & $\mathrm{HE}$ \\
\hline D & GC & 5.0 & $\mathrm{HE}$ \\
\hline E & LC & 5.0 & $\mathrm{HE}$ \\
\hline $\mathrm{F}$ & IGL & 5.0 & $\mathrm{HE}$ \\
\hline G & PBS & - & $\mathrm{HE}$ \\
\hline $\mathrm{H}$ & PBS & - & LE \\
\hline
\end{tabular}

$1: 1 \beta$-GC and $\beta$-LC (IGL) at doses of $2.5 \mathrm{mg} / \mathrm{kg}$ (groups A-C), $5.0 \mathrm{mg} / \mathrm{kg}$ (groups D-E), or PBS (group G). Group H was treated with PBS and fed an LE diet.

\section{Follow-up parameters}

Body and liver weight were evaluated at the end of study. Hepatic steatosis/steatohepatitis was evaluated by determining hepatic fat content via magnetic resonance imaging (MRI); examining liver biopsies; and measuring serum cholesterol, triglycerides, alanine aminotransferase (ALT), and aspartate aminotransferase (AST) levels.

\section{Serum levels of IFN- $\gamma$ and IL- I0}

Serum levels of IFN- $\gamma$ and interleukin (IL)-10 were determined by 'sandwich' enzyme-linked immunosorbent assay (ELISA) using commercial kits according to the manufacturer's instructions (Quantikine; R\&D Systems, Minneapolis, MN, USA).

\section{Hepatic fat content measurement by MRI}

P. obesus underwent MRI on day 21. Hepatic fat content was measured with a double-echo chemical shift gradient-echo sequence technique, which provides in-phase and out-of-phase images in a single acquisition for the assessment and quantification of fat. T1-weighted out-of-phase MRI is sensitive for detection of relatively small proportions of tissue fat. ${ }^{16,20}$ MR images were acquired with a 1.5-T system (Sigma LX; General Electric, Milwaukee, WI, USA). Double-echo MRI was performed with a repetition time of $125 \mathrm{msec}$, double echo times of 4 and $6.5 \mathrm{msec}$, and a flip angle of $80^{\circ}$. Imaging parameters included a section thickness of $3 \mathrm{~mm}$, a $13 \mathrm{~cm}$ field of view, and a 256 $\times 160$ matrix. Axial and coronal images were obtained. Signal intensity (SI) changes between in-phase and out-of-phase images were computed. The SI index was calculated as follows: SI index $=($ SIip - SIop $) /$ SIip $($ SIip $=$ in-phase SI; SIop = out-of-phase SI). Low SI index values indicate a smaller amount of tissue fat. 


\section{Measurement of serum AST, ALT, cholesterol, and triglyceride levels}

Serum fasting AST, ALT, glucose, insulin, cholesterol, and triglyceride levels were measured from cardiac blood at the end of the study period using standard techniques.

\section{Liver histology}

Liver segments from each sand rat were fixed in $10 \%$ neutral buffered formalin and then embedded in paraffin. Five sections ( $5 \mu \mathrm{m}$ thickness) were then stained with hematoxylin and eosin (H\&E). To visualize neutral lipids, livers were frozen in TissueTek OCT compound (Sakura Finetek USA Inc., Torrance, CA, USA), and sections were stained with Oil Red O.

\section{Statistical analysis}

Data were analyzed by one-way analysis of variance (ANOVA) using the Prism 4 software program (Graph-Pad Software Inc., San Diego, CA, USA). Data were considered significant if $P<0.05$.

\section{Results}

\section{$\beta$-glycosphingolipids decreased liver enzymes in P. obesus fed an HE diet}

Serum ALT levels were significantly increased in P. obesus fed an HE diet and treated with PBS (group G) compared with those fed an LE diet (group H) $(P<0.01)$. There was no statistically significant difference in serum AST levels between these groups. Significant decreases in serum AST and ALT levels were observed in GC-, LC-, and IGL-treated P. obesus fed an HE diet in groups A-F compared with PBS-treated animals (group G). Following treatment with $\beta$-glycosphingolipids, values were even lower than those observed in animals fed the LE diet (Figure 1A). Figure 1B shows photographs of H\&E and Oil Red O-stained liver biopsies from P. obesus fed an HE diet and treated with PBS (group G), manifesting increased hepatic steatosis, mild hepatic inflammation, and fibrosis, which were not present in littermates fed an LE diet (group H). Liver biopsies of GCtreated P. obesus (groups A and D) showed only minimal evidence of steatosis and no inflammation (Figure 1B).

\section{$\beta$-glycosphingolipids decreased hepatic fat content in P. obesus fed an HE diet}

As liver histology of GC-treated animals demonstrated a clear decrease in hepatic fat, we used MRI to quantify the total amount of intrahepatic fat in vivo. In PBS-treated P. obesus fed an HE diet (group G), hepatic fat content was increased when compared with animals fed an LE diet (group H)
(MRI SI index 19.3 vs $14.8, P$-value not significant [NS]; Figure 2). A reduction in the hepatic SI index in P. obesus compared with PBS-treated animals was observed only in animals treated with GC (groups A and D, 14.4 and 14.1, respectively); GC administration reduced the hepatic SI index of the P. obesus fed an HE diet to the levels of the those fed the LE diet (group H). No additional decrease in SI index was obtained when the animals were treated with a double dose of GC $(5 \mathrm{mg} / \mathrm{kg})$. The reduction in fat content is represented in the MR image from P. obesus fed an HE diet and treated with PBS (group G) and those treated with GC (group A) in Figure 2.

\section{$\beta$-glycosphingolipids decreased liver weight in P. obesus fed an HE diet}

Administration of $\beta$-glycosphingolipid to P. obesus fed an HE diet halted the increase in hepatic weight observed in the P. obesus fed an HE diet and treated with PBS (Figure 3). Mean liver weights and percentages of liver weight out of body weight of the $\beta$-glycosphingolipid-treated animals (groups A-D) were significantly lower than in group $\mathrm{G}$ (PBS-treated animals). However, when higher dosages of LC and IGL were administered, no statistically significant difference was observed when compared with controls (group G).

\section{$\beta$-glycosphingolipid decreased fasting serum cholesterol and triglyceride levels in P. obesus fed an HE diet}

Serum triglycerides and cholesterol were higher for P. obesus fed an HE diet and treated with PBS (group G) when compared with animals fed an LE diet (group H) (Figure 4). Administering LC or high doses of IGL decreased serum triglyceride levels in groups B, E, and F. Treatment with $\beta$-glycosphingolipid (except for low-dose GC) reduced cholesterol levels (Figure 4).

\section{Effect of $\beta$-glycosphingolipids on serum IFN- $\gamma$ and IL- 10 levels}

We studied the effect of $\beta$-glycosphingolipids on pro- and anti-inflammatory cytokines: IFN- $\gamma$ and IL-10. Figure 5 shows that administration of GC, LC, and IGL was associated with a decrease in IFN- $\gamma$ serum levels. Low-dose LC and high-dose IGL administration were associated with increased levels of IFN- $\gamma$. However, these changes were not statistically significant. For serum IL-10 levels, an HE diet induced an increase, but various treatments of $\beta$-glycosphingolipids did not significantly affect the IL-10 levels in P. obesus fed an HE diet. 

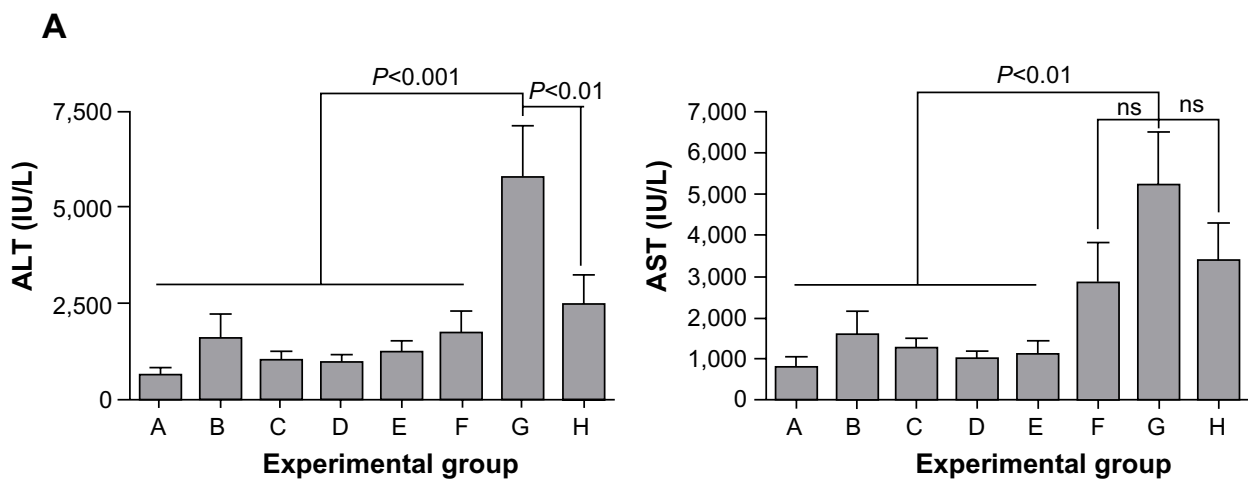

B
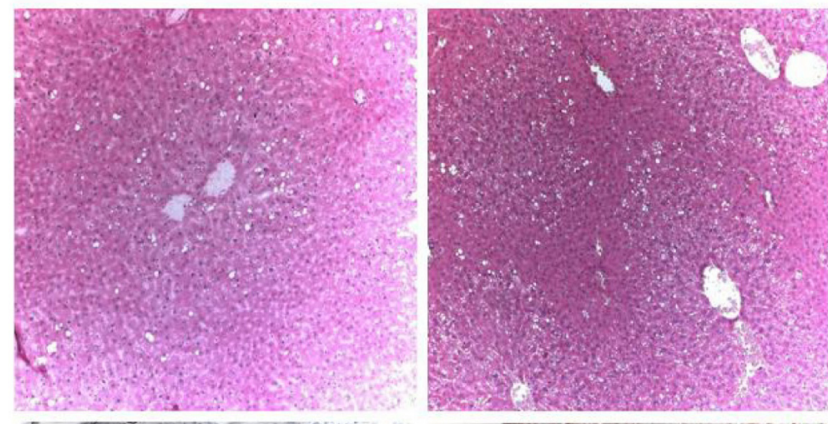

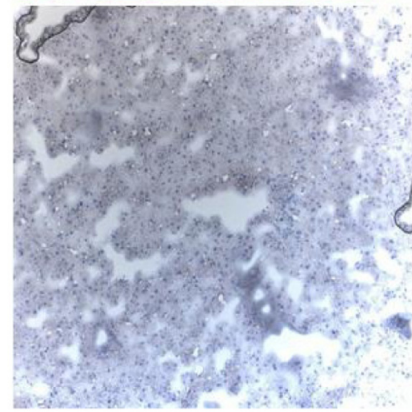

Group A: GC

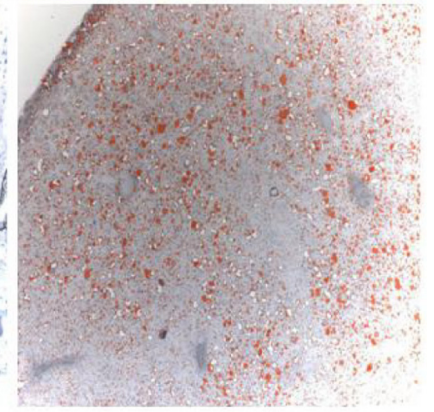

Group G: control

Figure I Effect of $\beta$-glycosphingolipids on liver injury and histology.

Notes: (A) Liver enzymes were measured in the serum of all the rats in all groups. Data are shown as means + standard error. (B) Histology in five liver sections was evaluated in each of the animals and by staining with H\&E (upper panel) and Oil Red O (lower panel). Representative liver biopsies from a group A animal and a group G animal $(\times 10$ magnification) reveal a significant decrease in fat content in the GC-treated animal.

Abbreviations: ALT, alanine aminotransferase; AST, aspartate aminotransferase; GC, $\beta$-glucosylceramide; H\&E, hematoxylin and eosin; ns, not significant.

\section{Discussion}

Hyperinsulinemic, hyperglycemic, and hypertriglyceridemic P. obesus manifested significant hepatic steatosis, elevated serum aminotransferase levels, mild hepatic inflammation, and fibrosis, all features found in NASH. Administration of $\beta$-glycosphingolipids significantly decreased hepatic injury, manifested by decreases in steatosis and inflammation. These effects were accompanied by a reduction in central body fat and were associated with a tendency for a decline in serum IFN- $\gamma$ levels.

The P. obesus is a useful model for NAFLD. It possesses a number of features that are reminiscent of the disease in human subjects, including the hepatic steatosis distribution pattern, the presence of hepatic inflammation and fibrosis, and an association with insulin resistance and hyperlipidemia. The ease of inducing NAFLD in this model, in which animals become diabetic after 2 weeks on an HE diet, further establishes the advantages of $P$. obesus in comparison with other experimental models for NAFLD less physiologically similar to human NAFLD pathogenesis. ${ }^{4}$

In our study we focus on hepatic steatosis, a feature that is not well studied in P. obesus. We found that administration of $\beta$-glycosphingolipids resulted in reduced hepatic steatosis and inflammation, which was associated with a decrease in IFN- $\gamma$ levels, suggesting an immune-mediated anti-inflammatory effect. These results are in line with our previous studies in 


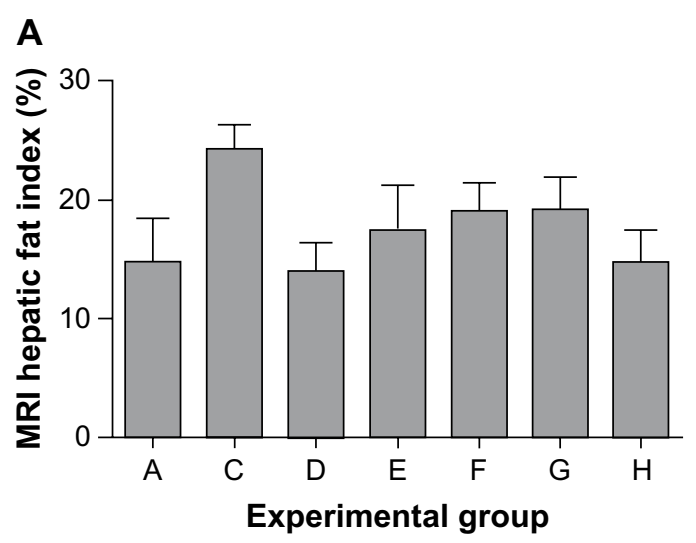

B

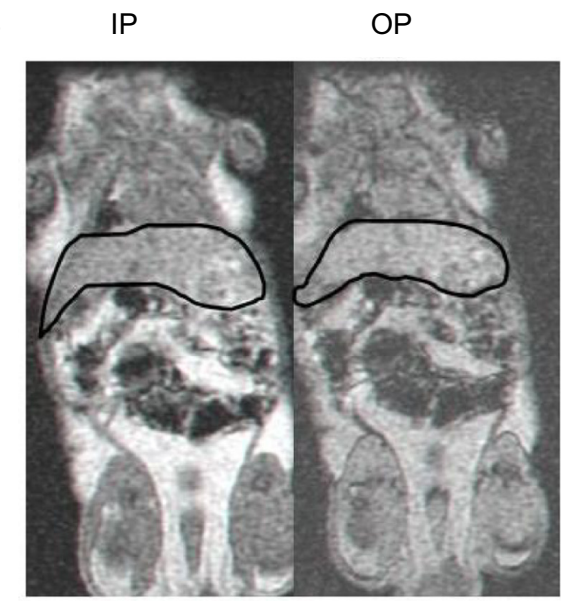

Group A: GC

SI: 14.8

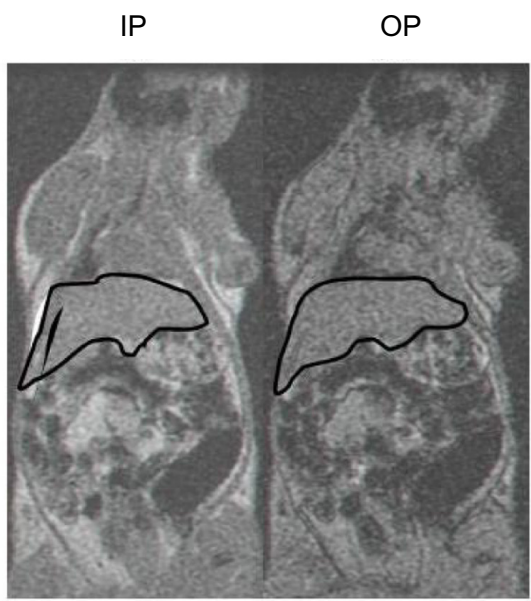

Group G: control

SI: 19.3

Figure 2 Effect of $\beta$-glycosphingolipids on liver fat content in Psammomys obesus fed a high-energy diet.

Notes: (A) MRI was used to quantify the amount of fat in treated $P$. obesus livers. The calculated MRI index was performed for each rat in each of the groups. Results are presented as means + standard error for each group. (B) A representative MR image from P. obesus fed a high-energy diet and treated with PBS (group G) or GC (group A). Abbreviations: GC, $\beta$-glucosylceramide; IP, in-phase; MRI, magnetic resonance imaging; OP, out-of-phase; PBS, phosphate buffered saline; SI, signal intensity.

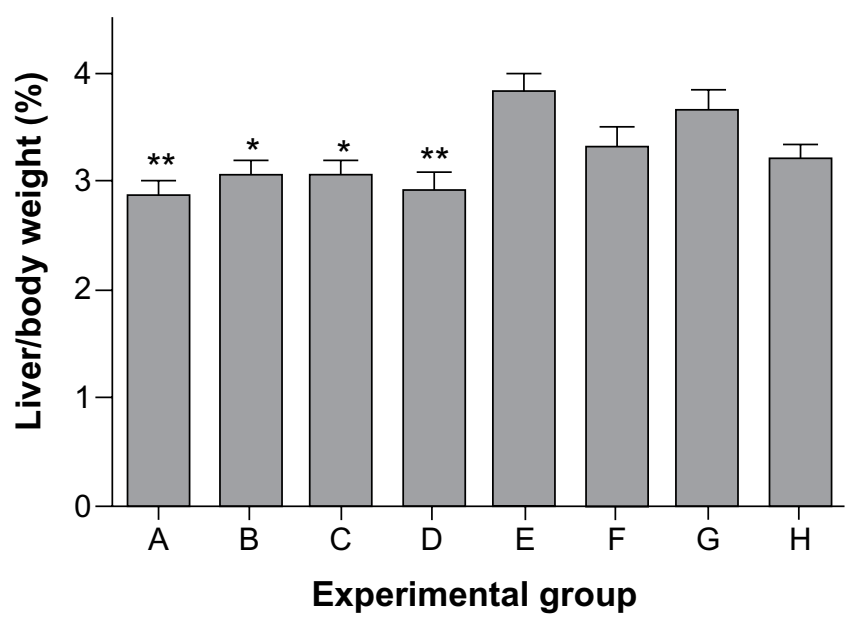

Figure 3 Effect of $\beta$-glycosphingolipids on liver weight in Psammomys obesus fed a high-energy diet.

Notes: Liver weight was evaluated in all of the animals in all of the groups, and the percentage of liver weight out of total body weight was calculated. $* P<0.05$, $* * P<0.0$ I. Data are shown as means + standard error. several animal models that demonstrated the beneficial effect of $\beta$-glycosphingolipids. ${ }^{19,21}$ Administering $\beta$-GC to leptindeficient $o b / o b$ mice ameliorated hepatic steatosis, lowered serum triglyceride levels, and normalized glucose tolerance curves. ${ }^{21}$ This effect was associated with an immune effect on T-lymphocyte subsets, manifested by a decrease in hepatic natural killer T-cells and an increase in hepatic cluster of differentiation (CD)-8+ T-lymphocytes. ${ }^{21}$

The contribution of immune-mediated mechanisms to the pathogenesis of NASH has been increasingly recognized. Adipose tissue secretes a number of adipocytokines that act locally or distally as inflammatory, immune, or hormonal signalers. ${ }^{22}$ The pro-inflammatory state in adipose tissue leads to local insulin resistance, including an impaired free fatty acid (FFA) release inhibition by insulin.

The association between hepatic steatosis and inflammation and features of the metabolic syndrome in P. obesus 

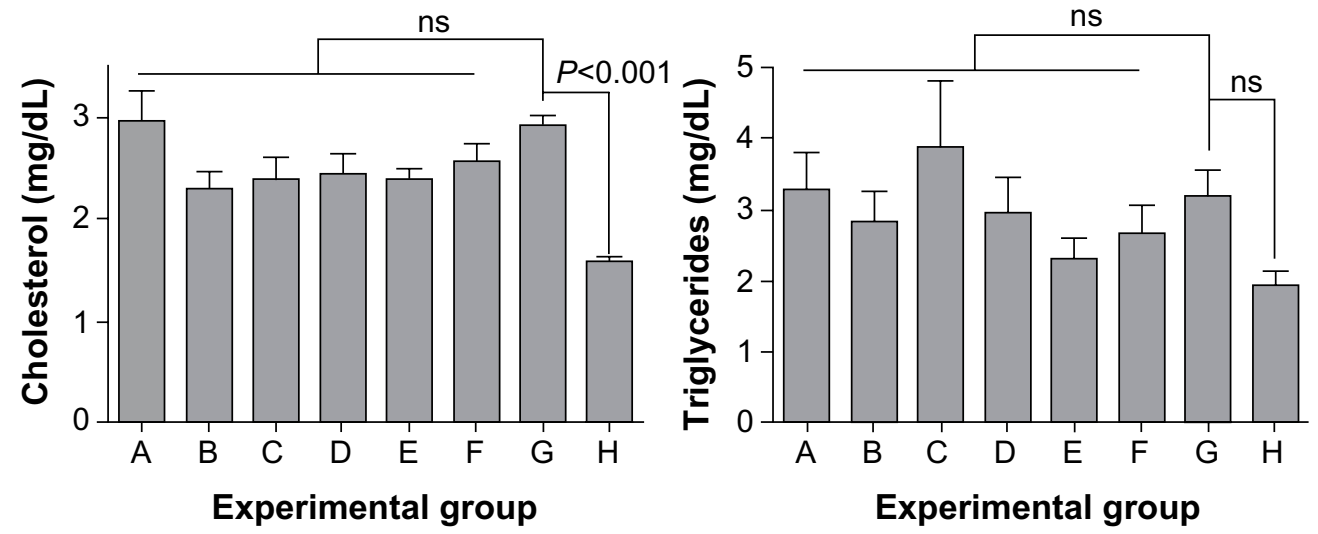

Figure 4 Effect of $\beta$-glycosphingolipids on serum cholesterol and triglyceride levels in Psammomys obesus fed a high-energy diet.

Notes: Serum levels of cholesterol and triglycerides were measured in all of the animals in all of the groups, and mean levels are presented. Data are shown as means + standard error.

Abbreviation: ns, not significant.

reinforces the concept of interactions among these conditions. ${ }^{5,23}$ Indeed, insulin resistance was shown to play a key role, in both the development of hepatic steatosis and in its progression to steatohepatitis. ${ }^{24}$ The mechanism involved increased release of FFAs from adipose tissue, which suggested a possible link between obesity, insulin resistance, and NASH. ${ }^{1,16,25-27}$ Following these assumptions, enhanced delivery of FFAs from visceral adipocytes into the portal system may contribute to reduced hepatic insulin clearance, increased hepatic gluconeogenesis, and triglyceride synthesis, as well as impaired insulin-mediated suppression of hepatic glucose output and induction of peripheral insulin resistance. ${ }^{25}$ As a result of these abnormal fatty acid metabolisms, fat accumulates in parenchymal liver cells in excess of the hepatic capacity for FFA metabolism. This may increase the mitochondrial synthesis of fatty acids and impaired secretion of triglycerides. Support for the assumption relating lipotoxicity and liver injury may be exhibited by the MCD high-fat diet model in which FFA accumulate despite substantial suppression of lipogenesis and induction of triglyceride synthesis genes. ${ }^{26}$

The disparities noted among the different $\beta$-glycosphingolipids and the relative advantage of GC over the other tested ligands can be explained by its higher affinity to the $\mathrm{CD} 1 \mathrm{~d}$ receptor on natural killer T-cells or dendritic cells. ${ }^{28}$ Alternatively, $\beta$-glycosphingolipids may exert an effect on hepatic steatosis that is independent of insulin resistance. More studies to investigate these hypotheses are warranted. In the Zucker diabetic fatty rat model, blood glucose level reduction was achieved by lowering glycosphingolipid levels using a GC synthase inhibitor, which affected peripheral insulin sensitivity without increasing insulin levels. ${ }^{29-31} \mathrm{In}$ the present study, $\beta$-glycosphingolipid level elevation may have affected $\beta$-cell function, with only a minor influence on
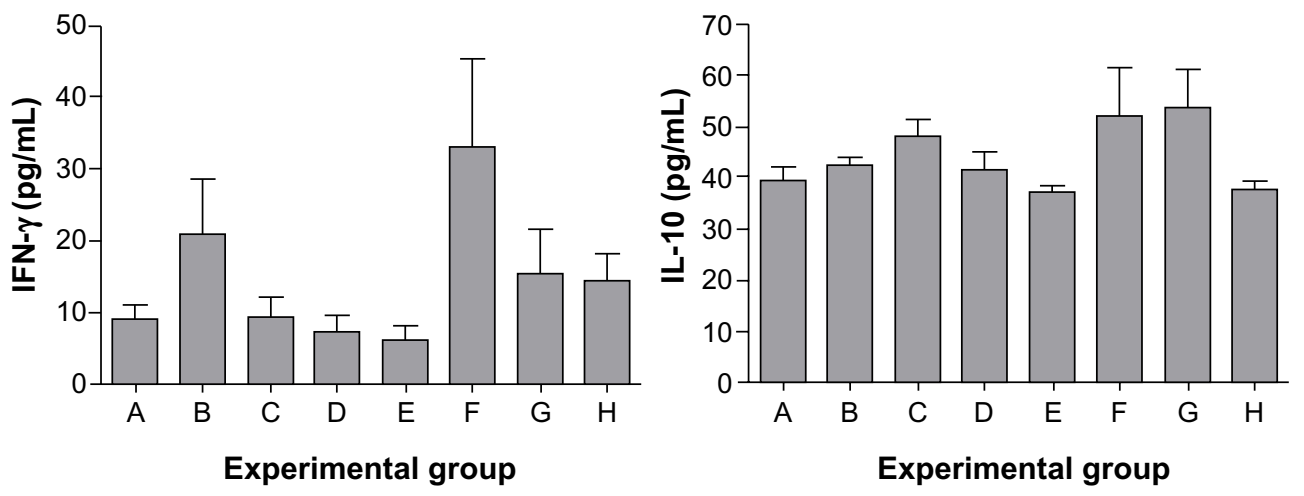

Figure 5 Effect of $\beta$-glycosphingolipids on serum levels of IFN- $\gamma$ and IL-I0.

Notes: Serum levels of IFN- $\gamma$ and IL- 10 were measured by ELISA in all mice in all groups. Data shown are means + standard error.

Abbreviations: ELISA, enzyme-linked immunosorbent assay; IFN, interferon; IL, interleukin. 
peripheral insulin resistance. GC and related glycosphingolipids have been implicated as causal elements in cell growth and regulation of hormonal signaling. ${ }^{32}$ In a diabetes model, increases in renal size and concentration of glucocerebroside and ganglioside GM3 were noted in parallel with an increase in ganglioside concentration. ${ }^{32}$ Glycosphingolipid formation was suggested to represent an important pathway for glucose utilization in early diabetic nephropathy. ${ }^{32}$ Administering $\beta$-glycosphingolipids may alter the levels of as-yet undefined gangliosides, thus altering these pathways.

In summary, we have shown that $\beta$-glycosphingolipids exert a remarkable beneficial effect on fatty liver in $P$. obesus, with alteration of body fat distribution that was associated with a decrease in fat accumulation and the associated liver inflammatory response. GC was recently found to be safe in a preliminary study in healthy human subjects ${ }^{33}$ and may prove to be a novel therapeutic modality for NAFLD and the metabolic syndrome.

\section{Disclosure}

This work was supported in part by the following grants: The Roaman-Epstein Liver Research Foundation (to YI), and ENZO Biochem, NYC, NY, USA. The authors have no other conflicts of interest in this work.

\section{References}

1. Farrell GC, Larter CZ. Nonalcoholic fatty liver disease: from steatosis to cirrhosis. Hepatology. 2006;43(2 Suppl 1):S99-S112.

2. Rosenau J, Hooman N, Rifai K, et al. Hepatitis B virus immunization with an adjuvant containing vaccine after liver transplantation for hepatitis B-related disease: failure of humoral and cellular immune response. Transpl Int. 2006;19(10):828-833.

3. London RM, George J. Pathogenesis of NASH: animal models. Clin Liver Dis. 2007;11(1):55-74, viii.

4. Portincasa P, Grattagliano I, Palmieri VO, Palasciano G. Nonalcoholic steatohepatitis: recent advances from experimental models to clinical management. Clin Biochem. 2005;38(3):203-217.

5. Leclercq IA. Pathogenesis of steatohepatitis: insights from the study of animal models. Acta Gastroenterol Belg. 2007;70(1):25-31.

6. Diehl AM. Lessons from animal models of NASH. Hepatol Res. 2005;33(2):138-144.

7. Kaiser N, Nesher R, Donath MY, et al. Psammomys obesus, a model for environment-gene interactions in type 2 diabetes. Diabetes. 2005; 54 Suppl 2:S137-S144.

8. Shafrir E, Ziv E, Kalman R. Nutritionally induced diabetes in desert rodents as models of type 2 diabetes: Acomys cahirinus (spiny mice) and Psammomys obesus (desert gerbil). ILAR J. 2006;47(3): 212-224.

9. Ziv E, Shafrir E, Kalman R, Galer S, Bar-On H. Changing pattern of prevalence of insulin resistance in Psammomys obesus, a model of nutritionally induced type 2 diabetes. Metabolism. 1999;48(12): 1549-1554.

10. Kalman R, Adler JH, Lazarovici G, Bar-On H, Ziv E. The efficiency of sand rat metabolism is responsible for development of obesity and diabetes. J Basic Clin Physiol Pharmacol. 1993;4(1-2):57-68.

11. Maislos M, Medvedovskv V, Sztarkier I, Yaari A, Sikuler E. Psammomys obesus (sand rat), a new animal model of non-alcoholic fatty liver disease. Diabetes Res Clin Pract. 2006;72(1):1-5.
12. Zoltowska M, Delvin E, Ziv E, Peretti N, Chartré M, Levy E. Impact of in vivo glycation of $L D L$ on platelet aggregation and monocyte chemotaxis in diabetic psammomys obesus. Lipids. 2004;39(1):81-85.

13. Zoltowska M, Ziv E, Delvin E, Lambert M, Seidman E, Levy E. Both insulin resistance and diabetes in Psammomys obesus upregulate the hepatic machinery involved in intracellular VLDL assembly. Arterioscler Thromb Vasc Biol. 2004;24(1):118-123.

14. Radin NS, Inokuchi J. Glucosphingolipids as sites of action in the chemotherapy of cancer. Biochem Pharmacol. 1988;37(15): 2879-2886.

15. Zhao H, Przybylska M, Wu IH, et al. Inhibiting glycosphingolipid synthesis ameliorates hepatic steatosis in obese mice. Hepatology. 2009;50(1):85-93.

16. Zhao H, Przybylska M, Wu IH, et al. Inhibiting glycosphingolipid synthesis improves glycemic control and insulin sensitivity in animal models of type 2 diabetes. Diabetes. 2007;56(5):1210-1218.

17. Bijl N, Sokolović M, Vrins C, et al. Modulation of glycosphingolipid metabolism significantly improves hepatic insulin sensitivity and reverses hepatic steatosis in mice. Hepatology. 2009;50(5):1431-1441.

18. Jennemann R, Rothermel U, Wang S, et al. Hepatic glycosphingolipid deficiency and liver function in mice. Hepatology. 2010;51(5): 1799-1809.

19. Zigmond E, Zangen SW, Pappo O, et al. Beta-glycosphingolipids improve glucose intolerance and hepatic steatosis of the Cohen diabetic rat. Am J Physiol Endocrinol Metab. 2009;296(1):E72-E78.

20. Yeh SH, Chuang H, Lin LW, Hsiao CY, Wang PW, Yang KD. Tai chi chuan exercise decreases $\mathrm{A} 1 \mathrm{C}$ levels along with increase of regulatory T-cells and decrease of cytotoxic T-cell population in type 2 diabetic patients. Diabetes Care. 2007;30(3):716-718.

21. Margalit M, Shalev Z, Pappo O, et al. Glucocerebroside ameliorates the metabolic syndrome in OB/OB mice. J Pharmacol Exp Ther. 2006;319(1):105-110.

22. Bulcão C, Ferreira SR, Giuffrida FM, Ribeiro-Filho FF. The new adipose tissue and adipocytokines. Curr Diabetes Rev. 2006;2(1):19-28.

23. Ikejima S, Sasaki S, Sashinami H, et al. Impairment of host resistance to Listeria monocytogenes infection in liver of $\mathrm{db} / \mathrm{db}$ and $\mathrm{ob} / \mathrm{ob}$ mice. Diabetes. 2005;54(1):182-189.

24. Chitturi S, Abeygunasekera S, Farrell GC, et al. NASH and insulin resistance: Insulin hypersecretion and specific association with the insulin resistance syndrome. Hepatology. 2002;35(2):373-379.

25. Choudhury J, Sanyal AJ. Insulin resistance and the pathogenesis of nonalcoholic fatty liver disease. Clin Liver Dis. 2004;8(3): $575-594$, ix

26. Larter CZ, Yeh MM, Haigh WG, et al. Hepatic free fatty acids accumulate in experimental steatohepatitis: role of adaptive pathways. J Hepatol. 2008;48(4):638-647.

27. Koda M, Kawakami M, Murawaki Y, Senda M. The impact of visceral fat in nonalcoholic fatty liver disease: cross-sectional and longitudinal studies. J Gastroenterol. 2007;42(11):897-903.

28. Chun T, Page MJ, Gapin L, et al. CD1d-expressing dendritic cells but not thymic epithelial cells can mediate negative selection of NKT cells. J Exp Med. 2003;197(7):907-918.

29. Aerts JM, Ottenhoff R, Powlson AS, et al. Pharmacological inhibition of glucosylceramide synthase enhances insulin sensitivity. Diabetes. 2007;56(5):1341-1349.

30. Du X, Zheng G, Jin H, et al. The adjuvant effects of co-stimulatory molecules on cellular and memory responses to HBsAg DNA vaccination. J Gene Med. 2007;9(2):136-146.

31. Tagami S, Inokuchi Ji J, Kabayama K, et al. Ganglioside GM3 participates in the pathological conditions of insulin resistance. $J$ Biol Chem. 2002;277(5):3085-3092.

32. Zador IZ, Deshmukh GD, Kunkel R, Johnson K, Radin NS, Shayman JA. A role for glycosphingolipid accumulation in the renal hypertrophy of streptozotocin-induced diabetes mellitus. J Clin Invest. 1993;91(3): 797-803.

33. Zigmond E, Lalazar G, Pappo O, et al. Treatment of non-alcoholic steatohepatitis by B-glucosylceramide: a phase I/II clinical study. Hepatology. 2006;44 Suppl:180A. 
Journal of Inflammation Research

Dovepress

\section{Publish your work in this journal}

The Journal of Inflammation Research is an international, peer-reviewed open-access journal that welcomes laboratory and clinical findings on the molecular basis, cell biology and pharmacology of inflammation including original research, reviews, symposium reports, hypothesis formation and commentaries on: acute/chronic inflammation; mediators of inflamma-

tion; cellular processes; molecular mechanisms; pharmacology and novel anti-inflammatory drugs; clinical conditions involving inflammation. The manuscript management system is completely online and includes a very quick and fair peer-review system. Visit http://www.dovepress.com/ testimonials.php to read real quotes from published authors.

Submit your manuscript here: http://www.dovepress.com/journal-of-inflammation-research-journal 